\title{
تأثير تداخل أسلوب التضمين بأسلوب التبادلي في أداء مهارة التصويب من القفز عالياً
}

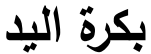

\author{
أم.د. محمد محمود كاظم \\ كلية التربية البلنية وعلوم الرياضية - جامعة بغداد \\ mohmood65@gmail.com
}

(00964) 07701189787

\author{
بلال عبدالمنعم مطر \\ مدرس/ المديرية العامة لتربية ميسان \\ bilalmunem@gmail.com
}

(00964) 07705575267

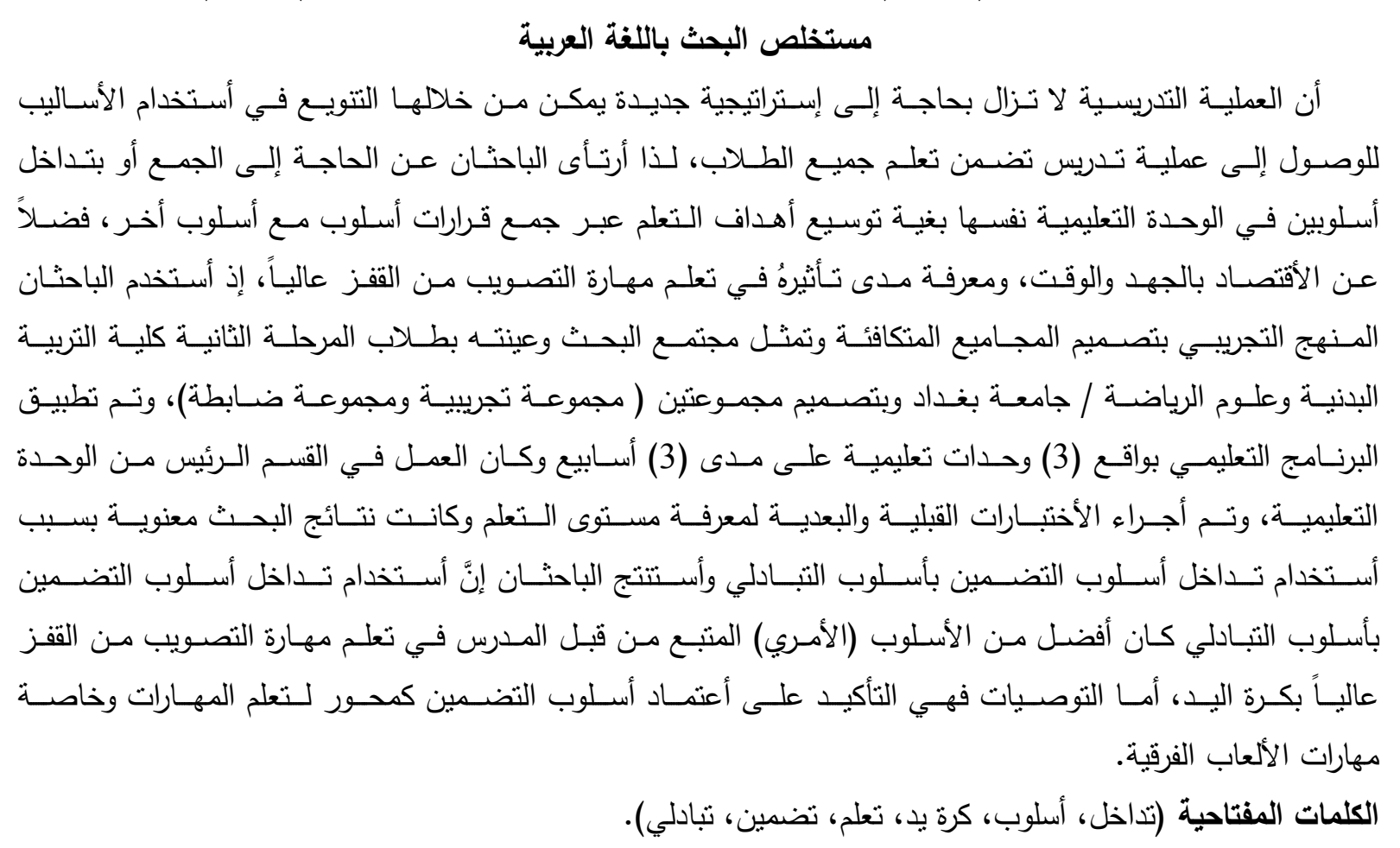

\section{ABSTRACT \\ The Effect of Inclusion Style And Reciprocal Style in Performing Jump Shot in Handball \\ Bilal Abdul Monam \\ Asst. Prof. Dr. Mohammed Muhmood \\ College of Physical Education and Sports \\ Sciences - University of Baghdad}

Teaching as a process still requires new strategies so as to include all students in the learning process. The researchers combined inclusion and reciprocal styles together in one teaching session to benefit from both styles, save time and effort and to identify their effect on learning handball jump shot. The researchers used the experimental method on sophomore college of physical education and sport sciences college. The teaching program consisted of (3) teaching session for three weeks. The results showed significant effects of using inclusion and reciprocal style yet the reciprocal style was better that command style followed by the teacher in learning jump shot in handball. Finally the researchers recommended using inclusion style for learning skills and specially team sport skills.

Keywords : Inclusion style, handball, Learning, reciprocal. 
أن تطـور الأسـاليب التـريسـية تجعـل المـتمـين فـي الثـأن التعليمسي مـن البـاحثين التربـويين والمتخصصـين

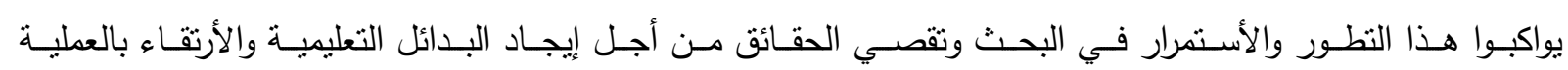

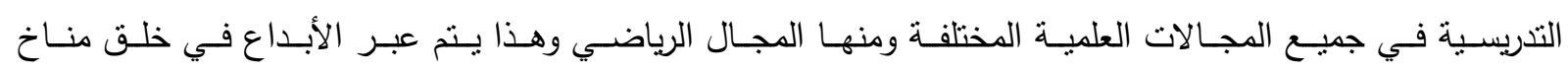
تعليمي أنموذجي مرغوب به في نتظيم مختلف الفعاليات والنشاطات ضمن الدروس التعليمية.

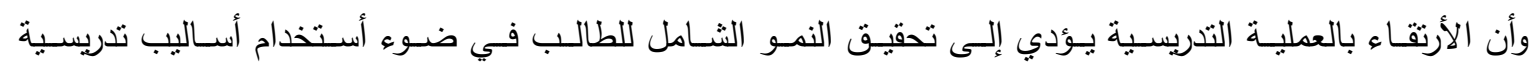

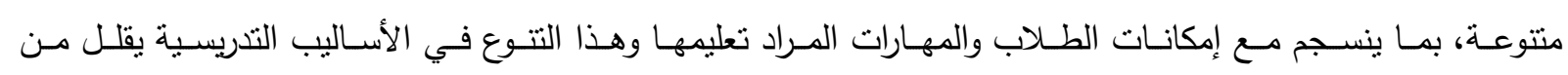

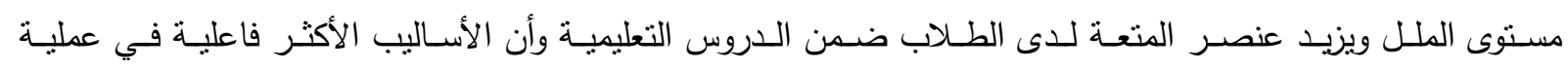

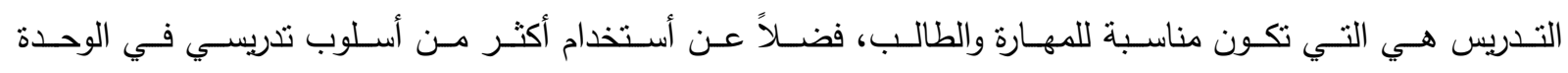

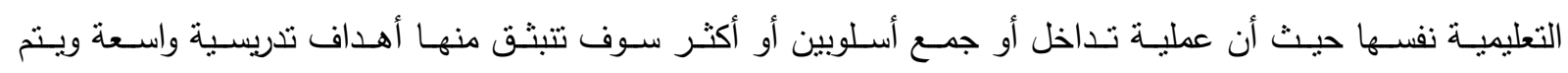

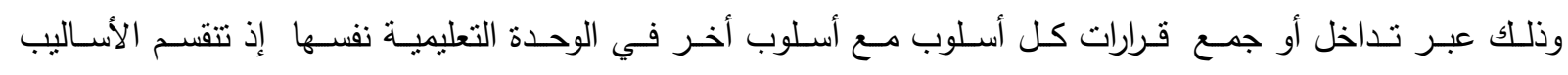

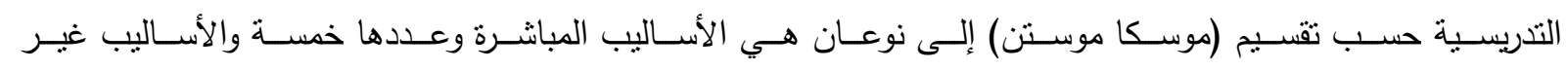

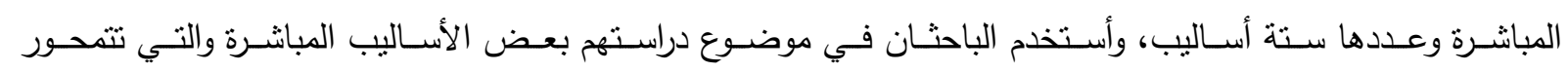
حول المدرس وهي أسلوب(التضمين، التبادلي) •

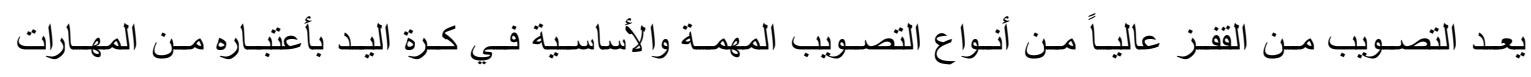

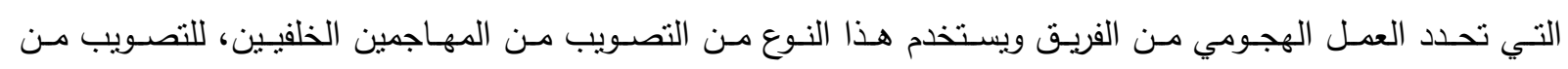

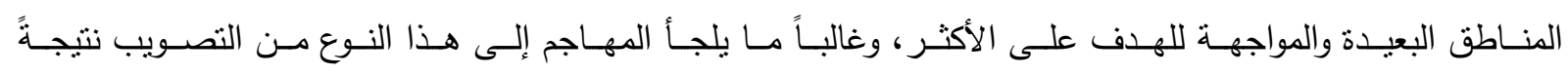

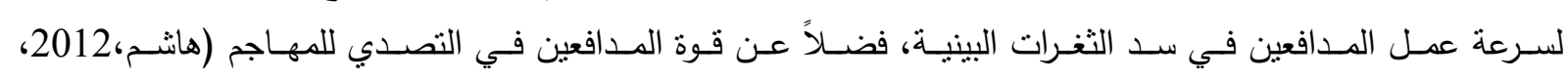

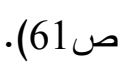

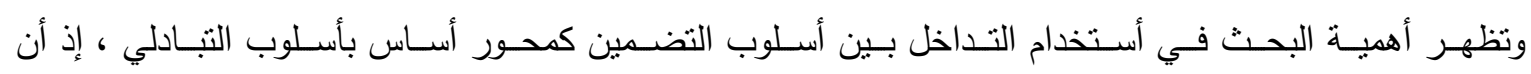

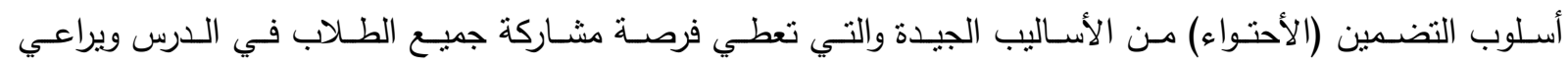

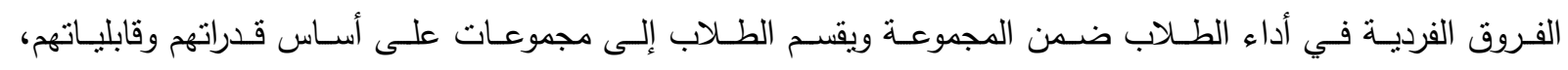

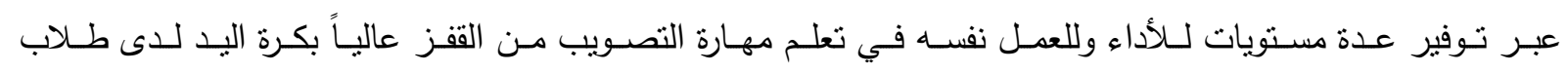

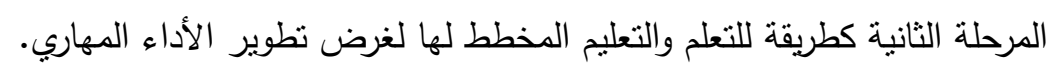

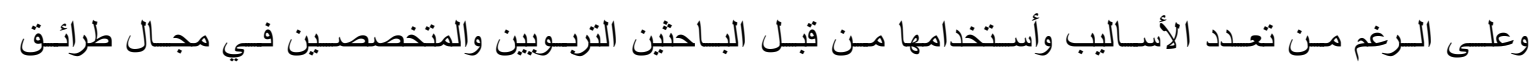

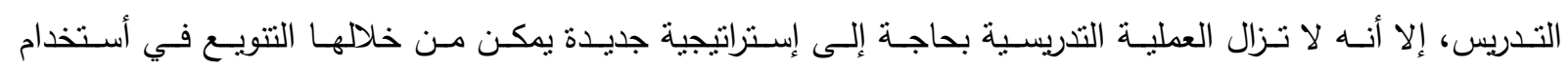

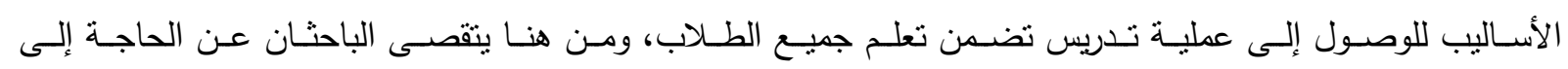

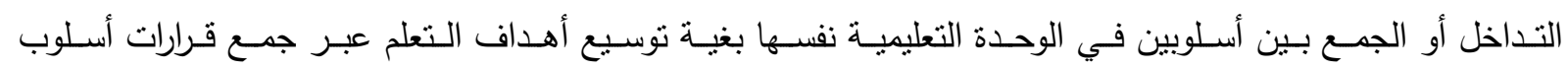

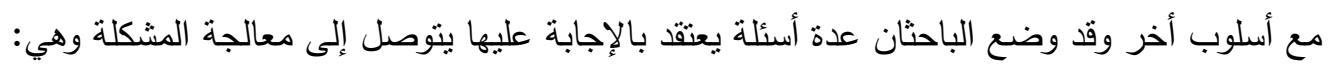

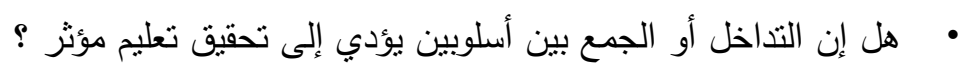

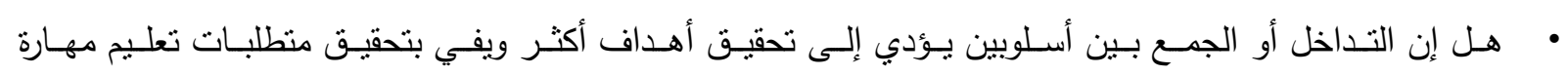
التصويب من الققز عالياً بكرة اليد ؟

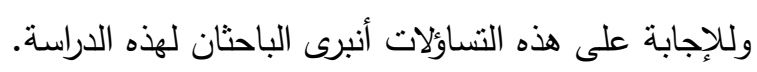

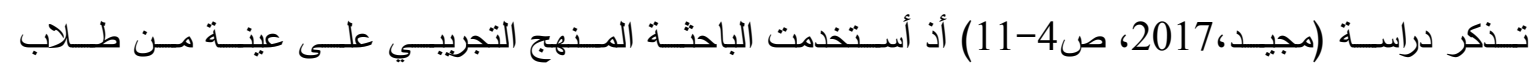

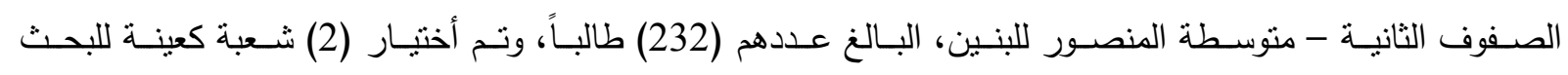

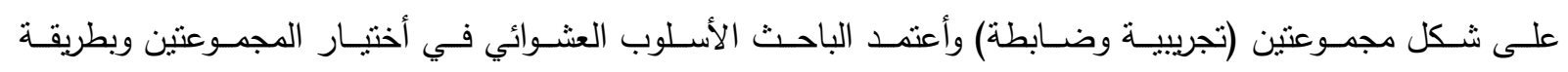




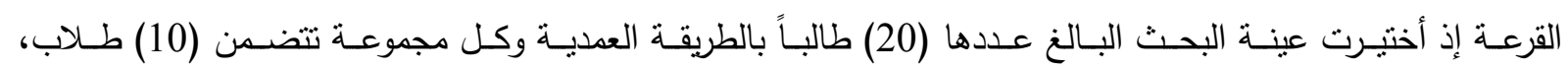

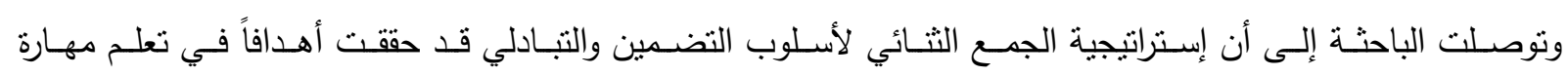
التصويب السلمي لدى عينة البحث.

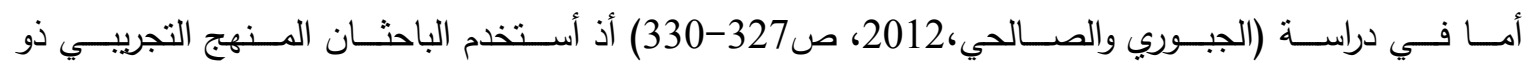

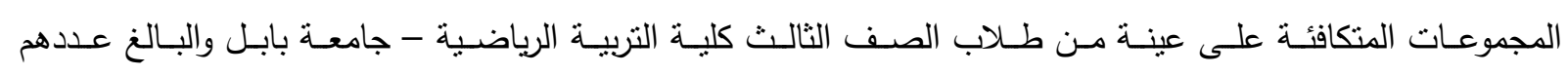

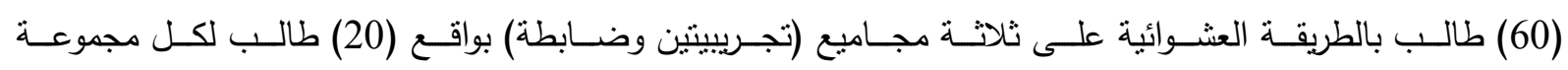

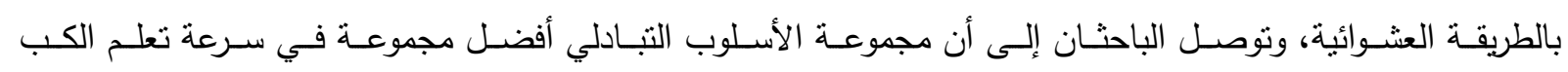
على جهاز العقلة.

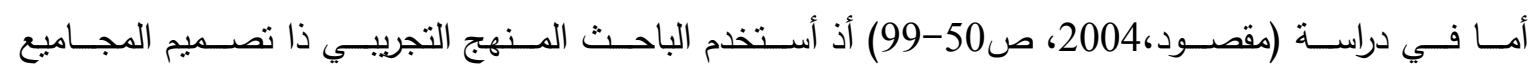

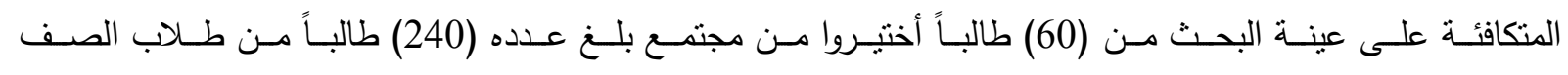

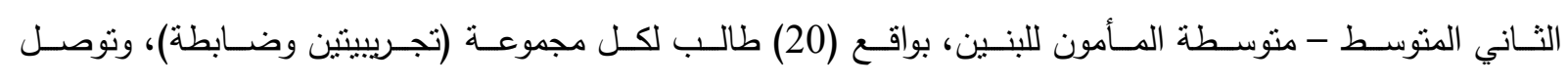

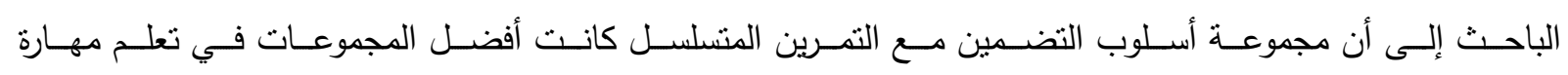
المناولة.

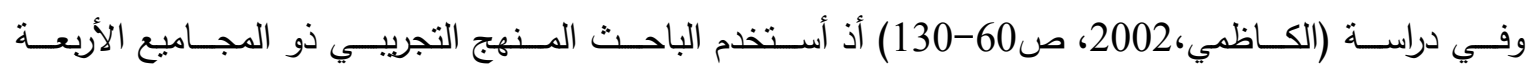
على عينـة مـن طـلاب المرحلـة الثالثـة في كليـة التربيـة الرياضـية - جامعـة بغـداد، (80) طالب بالطريقـة العشـوائية

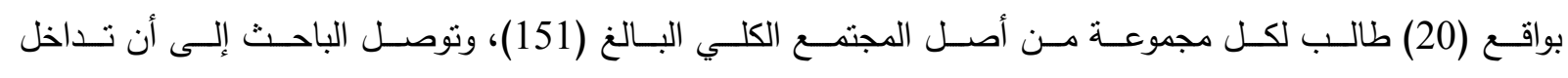

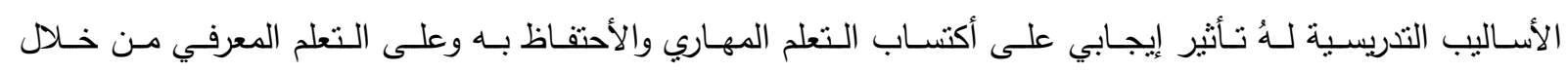
أستخدام الخيارات التتظيمية المكانية للمجاميع الأربع.

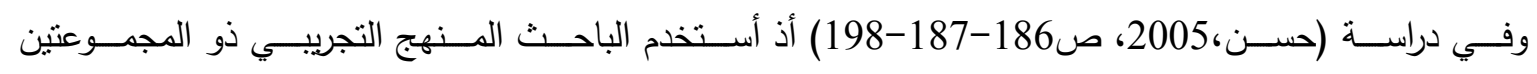

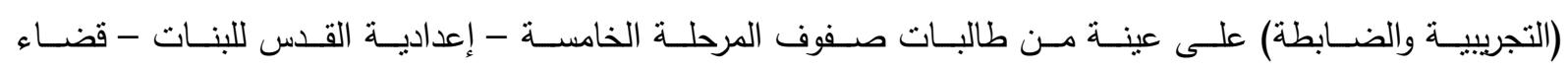

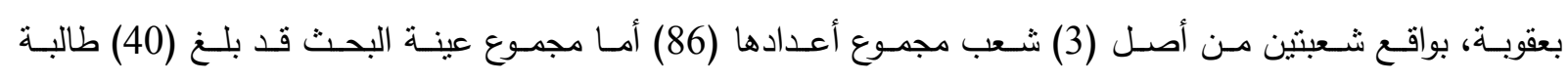

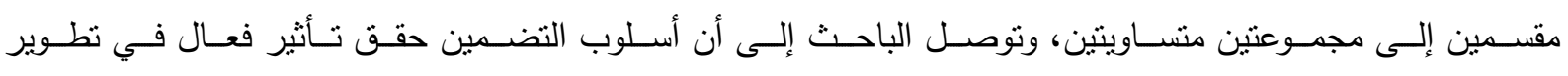

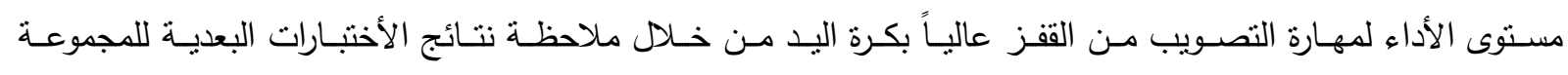
التجريبية. وفـي دراســة (فـتلاوي،2015، ص44-78) أذ أســتخدم الباحـث المـنهج التجريبـي ذو المجــوعنين التجـريبيتين

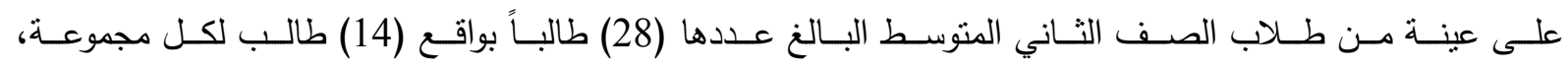

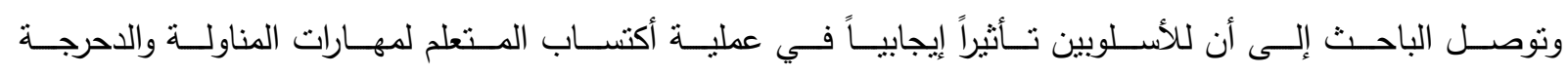
والإخماد.

\section{الطريقة والأدوات:}

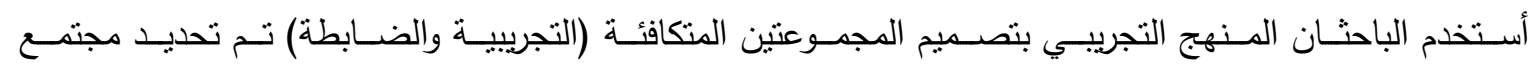
البحـث بالطريقـة العمديـة البـالغ عـددهم (51) طالـب وبنسـبة (26.56\%) مـن طـلاب المرحلـة الثانيـة فـي كليـة

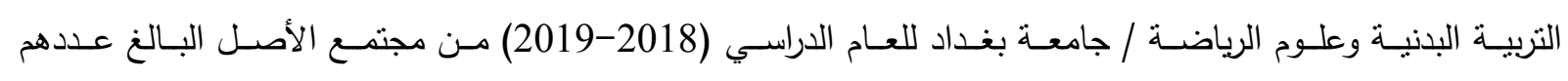

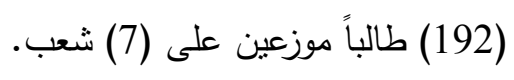

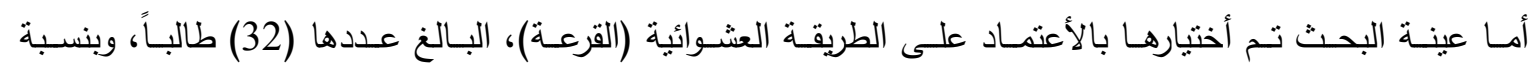

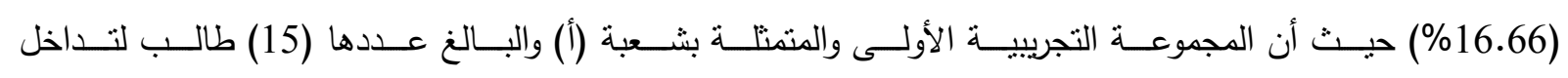


أســلوب التضــمين والتبـادلي، أمــا المجموعـة الثانيــة الضـابطة والمتمتلــة بثـعبة (ز) والبـالغ عـددها (17) طالـب

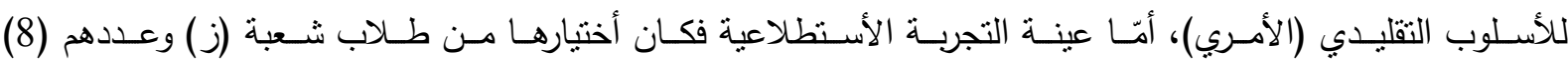
طلاب والجدول (1) يبين مجتمع البحث وعينته. الجدول (1) يبين مجتمع البحث وعينته

\begin{tabular}{|c|c|c|c|c|c|c|}
\hline \multirow{2}{*}{ لعينة البحثة المؤية } & \multirow{2}{*}{ عينة } & \multicolumn{2}{|c|}{ عدد الطلاب المستبعدين } & \multirow{2}{*}{ كدد الطلاب في شعبة } & \multirow{2}{*}{ عدد } & \multirow[b]{2}{*}{ المرحلة } \\
\hline & & الأستطلاعية التجربة & الممارسين & & & \\
\hline \multirow{8}{*}{$\% 16.66$} & 15 & - & 9 & 24 & أ & \multirow{7}{*}{ الثانية } \\
\hline & & & & 27 & ب & \\
\hline & & & & 29 & ج & \\
\hline & & & & 28 & د & \\
\hline & & & & 28 & هـ & \\
\hline & & & & 29 & و & \\
\hline & 17 & 8 & 2 & 27 & j & \\
\hline & 32 & 8 & 11 & 192 & 7 & المجموع \\
\hline
\end{tabular}

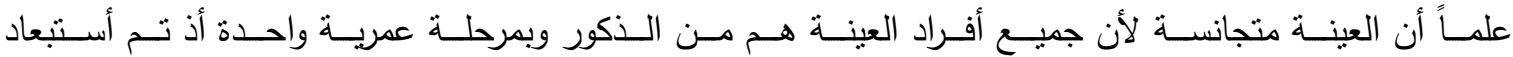

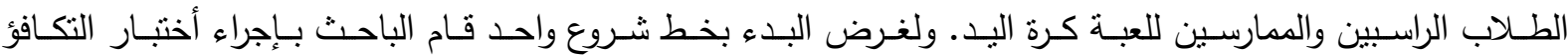
لمجـاميع البحث بأسـتخدام أختبـار (T) عبـر الأختبـار القبلـي لمهـارة التصـويب مـن القفز عاليـاً، والجدول (2) يبـين ذلك.

الجدول (2) يبين الوسط الحسابي والأنحراف المعياري وقيمة (T) المحسوية لمهارة التصويب من القفز عالياً في الأختبار القبلي للمجموعة التجريبية والمجموعة الضابطة

\begin{tabular}{|c|c|c|c|c|c|c|c|}
\hline \multirow{2}{*}{ الد لالة } & \multirow{2}{*}{ Sig } & \multirow{2}{*}{ 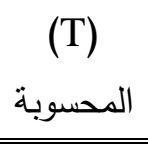 } & \multicolumn{2}{|c|}{ المجموعة الضابطة } & \multicolumn{2}{|c|}{ المجموعة التجريبية } & \multirow{2}{*}{ المتغيرات } \\
\hline & & & $\varepsilon$ & س & $\varepsilon$ & س س & \\
\hline غعنوي & .935 & .082 & .73033 & 3.6447 & .67871 & 3.6653 & التقويب من عالياً \\
\hline
\end{tabular}

معنوي > (0.05) عند درجة حرية (30) وتحت مستوى دلالة (0.05). مـن خـلال الجدول (2) تبـين عـدم وجـود فـروق معنويـة بـين المجمـوعتين (التجريبيـة والضــابطة) فـي مهـارة

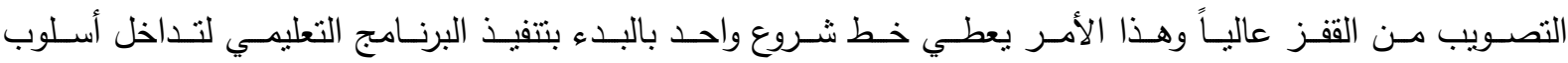
التضمين بأسلوب التبادلي لتعليم الطلاب مهارة التصويب من القفز عالياً.

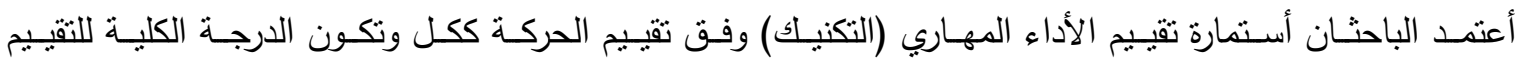

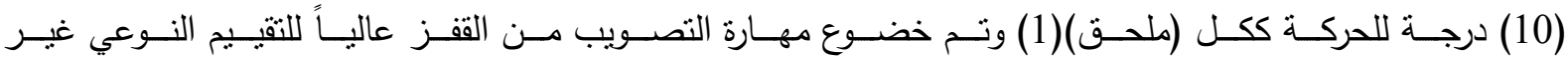

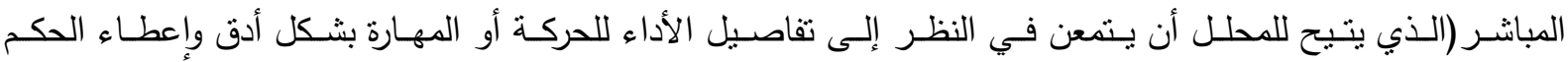

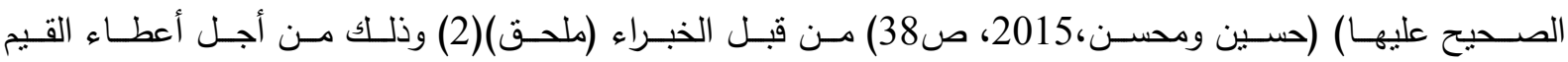

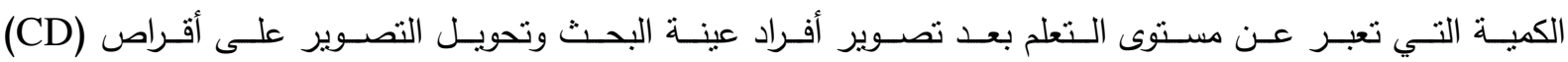
للأختبارات القبلية والبعدية. 
آلية أداء أختبار التصويب من القفز عالياً: تكون آلية أداء الأختبار لمهارة التصويب من الققز عالياً بإعطاء محاولنتين

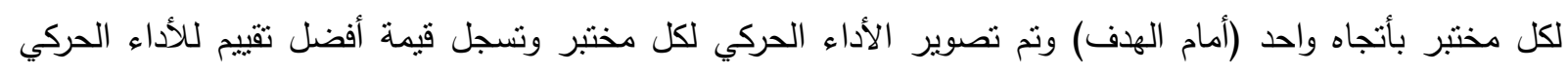
للمختبر من قبل الخبير في أستمارة تقييم الأداء للحركة ككل.

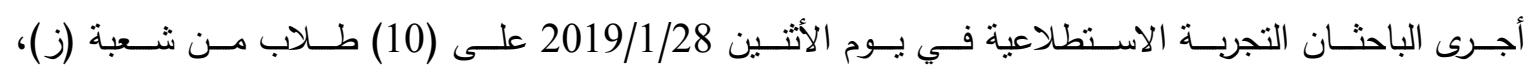

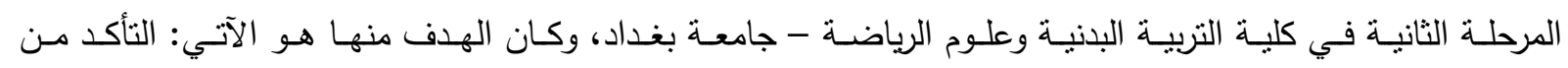

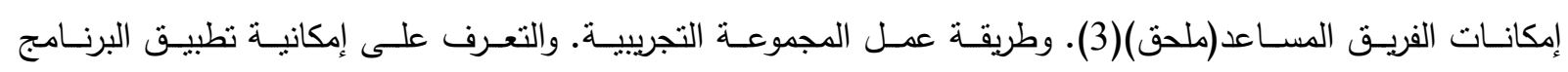
التعليمي باستخدام تداخل أسلوب التضمين بأسلوب التبادلي

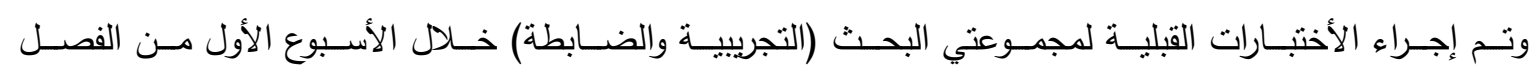

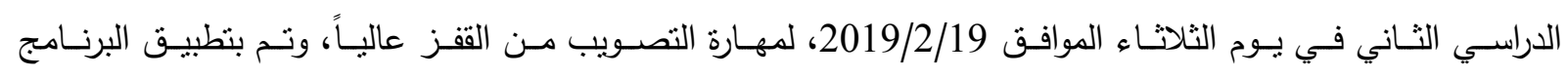

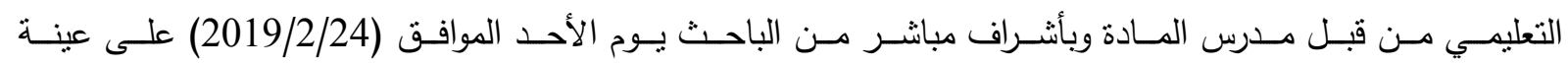

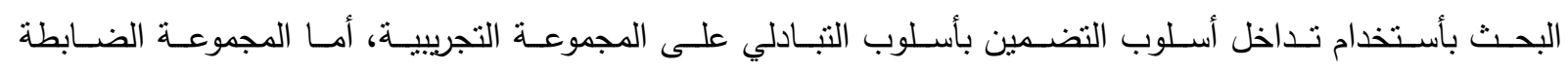

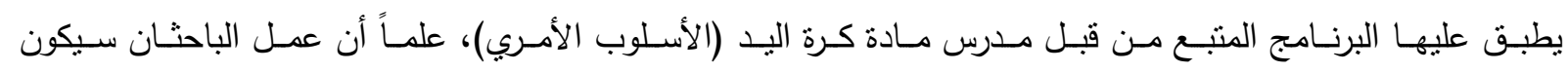

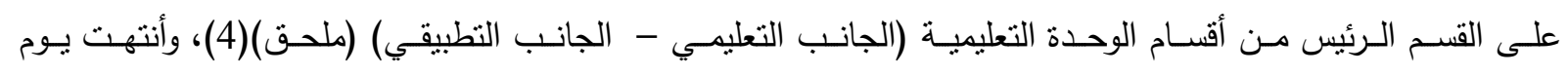

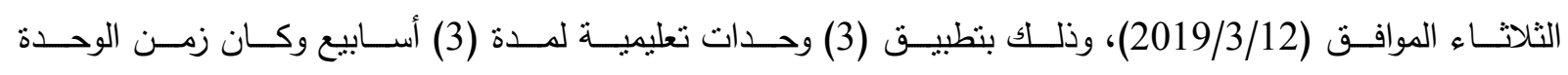

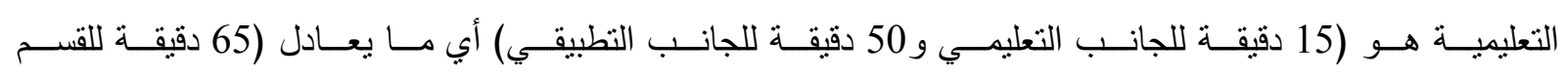

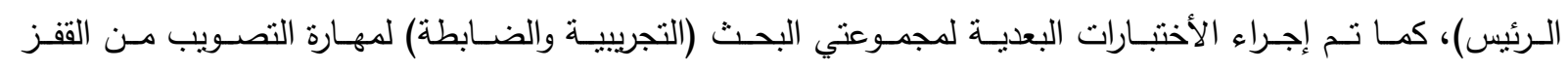

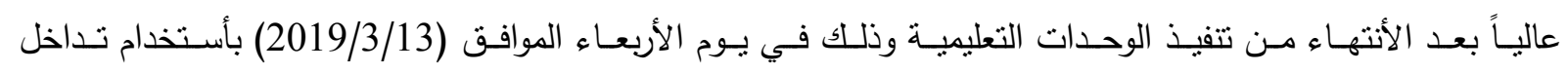

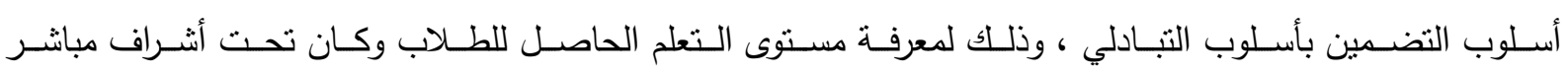

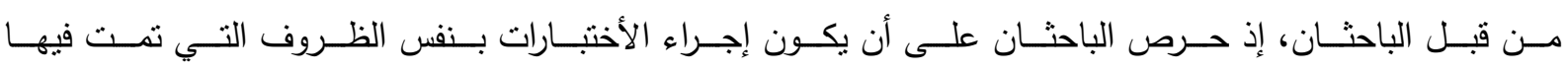

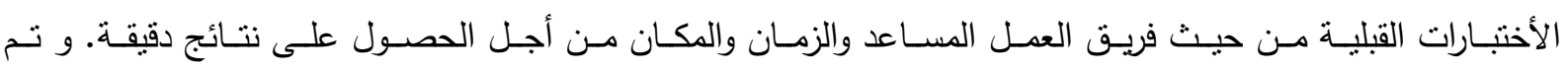

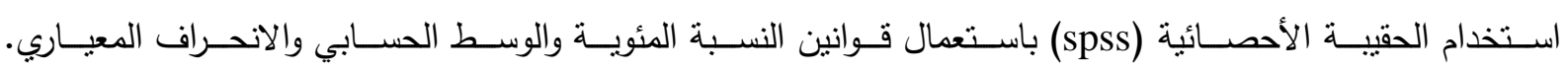
واختبار (T. Test) للعينات المستقلة واختبار (T. Test) للعينات غير المستقلة.

التنائج: الجدول (3) يبين الوسط الحسابي والأنحراف المعياري وقيمة (T) المحسوبة لمهارة التصويب من القفز عالياً في الأختبارين القبلي والبعدي للمجموعة التجريبية

\begin{tabular}{|c|c|c|c|c|c|c|c|c|c|}
\hline \multirow{2}{*}{$\begin{array}{l}\overline{7} \\
\text { 光 }\end{array}$} & \multirow{2}{*}{ Sig } & \multirow{2}{*}{ المحسوبة } & \multirow{2}{*}{ ف هـ } & \multirow{2}{*}{ نَ } & \multicolumn{2}{|c|}{ الأختبار البعدي } & \multicolumn{2}{|c|}{ الأختبار القبلي } & \multirow{2}{*}{ المتغيرات } \\
\hline & & & & & $\varepsilon$ & س & $\varepsilon$ & س & \\
\hline$\frac{3}{9}$ & .000 & 12.006 & .23861 & 2.86467 & .66273 & 6.5300 & .67871 & 3.6653 & من القفز \\
\hline
\end{tabular}

معنوي > (0.05) عند درجة حرية (14) وتحت مستوى دلالة (0.05). 
الجدول (4) يبين الوسط الحسابي والأنحراف المعياري وقيمة (T) المحسوبة لمهارة التصويب من القفز عالياً في الأختبارين القبلي والبعدي للمجموعة الضابطة

\begin{tabular}{|c|c|c|c|c|c|c|c|c|c|}
\hline \multirow[t]{2}{*}{$\overline{\overline{7}}$} & \multirow{2}{*}{ Sig } & \multirow{2}{*}{$\begin{array}{c}\text { (T) } \\
\text { المحسوبة }\end{array}$} & \multirow{2}{*}{ ف هـ } & \multirow{2}{*}{ فَ } & \multicolumn{2}{|c|}{ الأختبار البعدي } & \multicolumn{2}{|c|}{ الأختبار القبلي } & \multirow{2}{*}{ المتغيرات } \\
\hline & & & & & $\varepsilon$ & س & $\varepsilon$ & س & \\
\hline$\frac{3}{y}$ & .000 & 10.442 & .08461 & .88353 & .73593 & 4.5282 & .73033 & 3.6447 & الققز عالياً من \\
\hline
\end{tabular}

معنوي > (0.05) عند درجة حرية (16) وتحت مستوى دلالة (0.05).

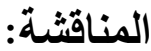

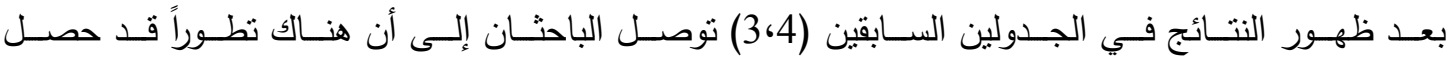

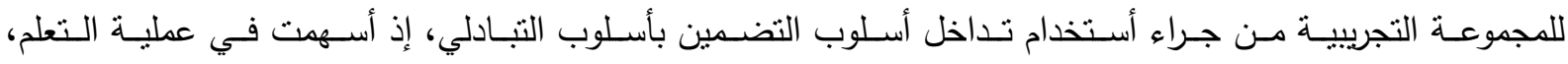

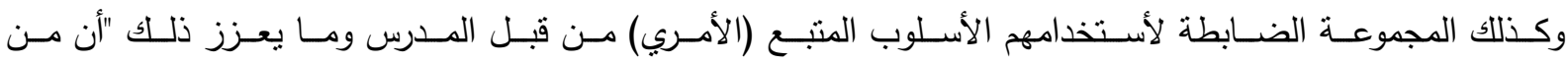

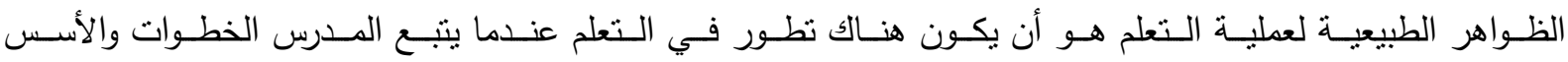

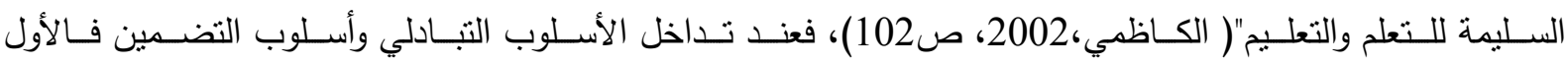

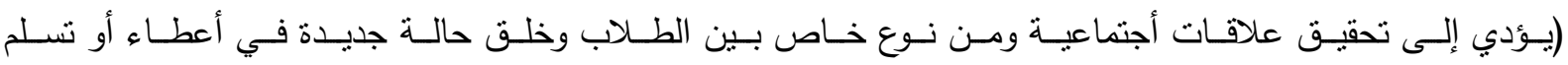

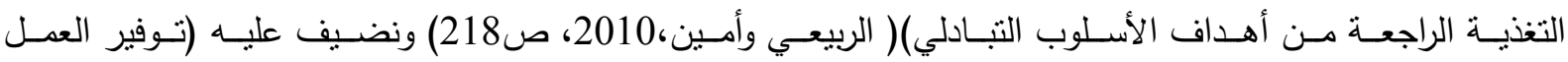

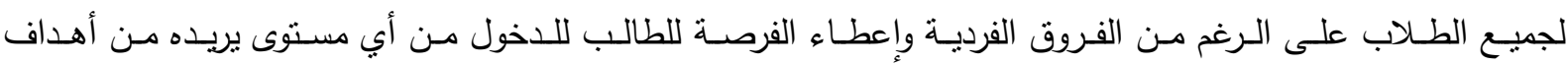

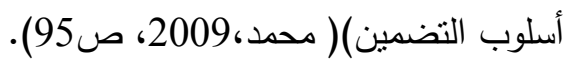
الجدول (5) يبين الوسط الحسابي والأنحراف المعياري وقيمة (T) المحسوبة لمهارة التصويب من القز عالياً في الأختبار البعدي للمجموعة التجريبية والمجموعة الضابطة ولمبه

\begin{tabular}{|c|c|c|c|c|c|c|c|}
\hline \multirow{2}{*}{ الدلالة } & \multirow{2}{*}{ Sig } & \multirow{2}{*}{$\begin{array}{c}\text { المحسوبة } \\
\text { المسو }\end{array}$} & \multicolumn{2}{|c|}{ المجموعة الضابطة } & \multicolumn{2}{|c|}{ المجموعة التجريبية } & \multirow{2}{*}{ المتغيرات } \\
\hline & & & $\varepsilon$ & س & $\varepsilon$ & س & \\
\hline معنوي & .000 & 8.041 & .73593 & 4.5282 & .66273 & 6.5300 & التصويب من القز عالياً \\
\hline
\end{tabular}

معنوي > (0.05) عند درجة حرية (30) وتحت مستوى دلالة (0.05).

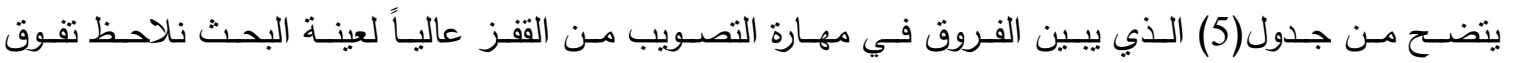

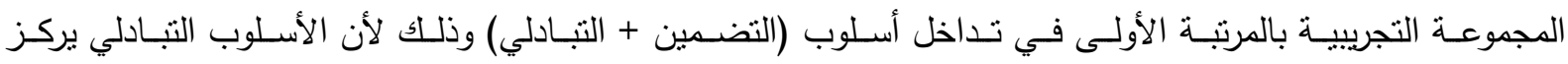

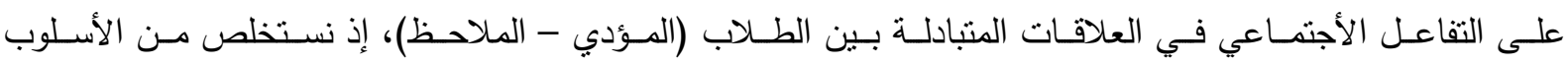

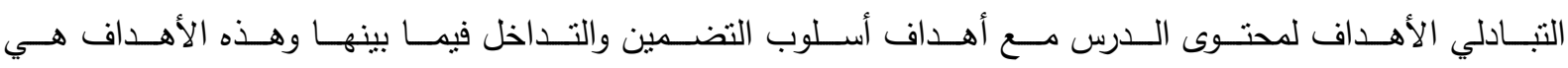

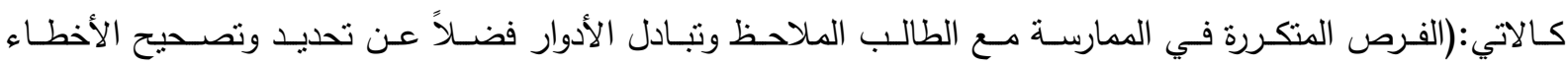

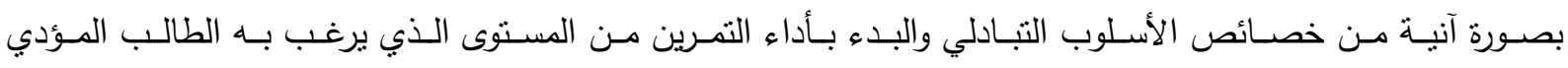

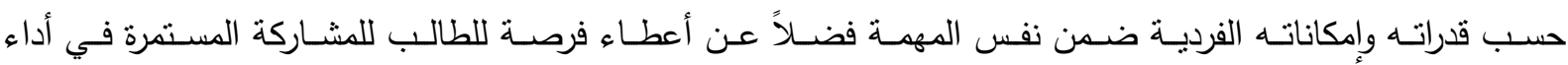

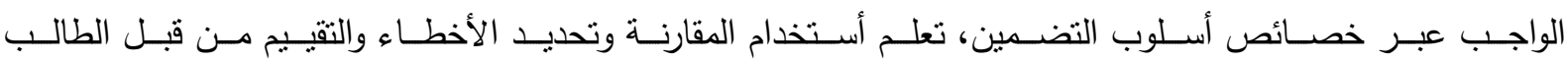




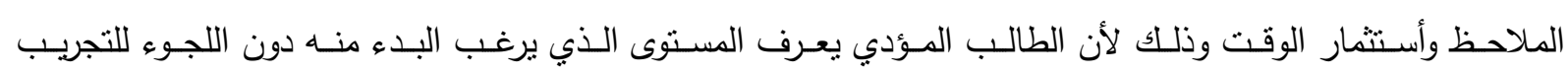
في كيفية الأداء).

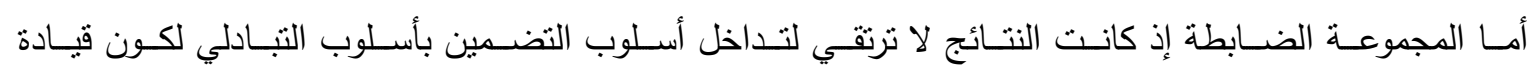

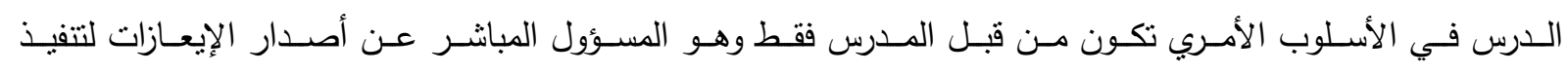

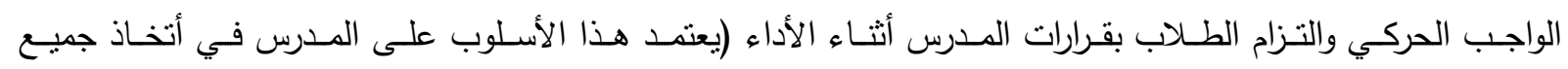

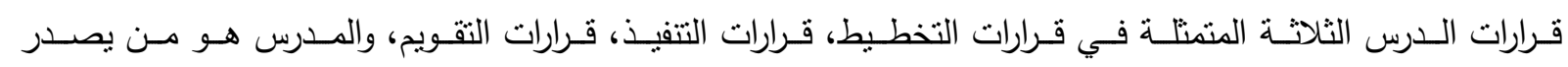

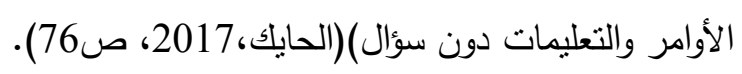

\section{المصادر}

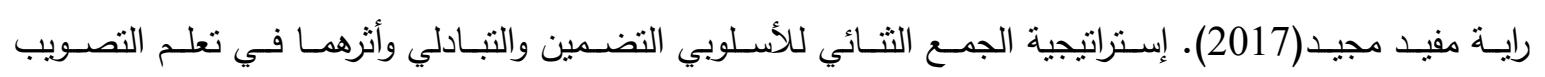

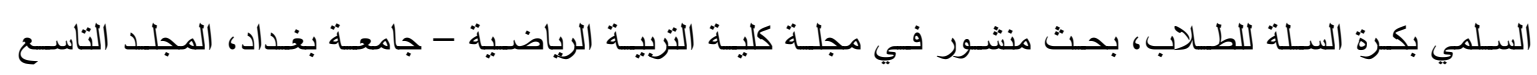
والعشرون، العدد الثاني.

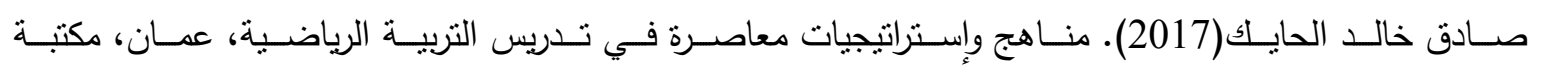
أمبة.

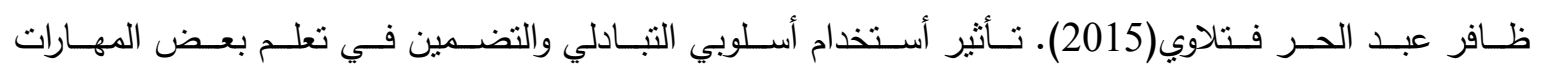
الأساسية بكرة القدم لطلاب الصف الثاني متوسط، رسالة ماجسنير، جامعة بغداد، كلية التربية الرياضية.

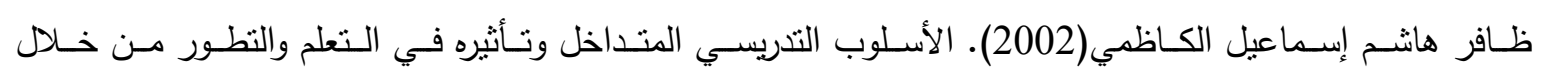
الخيارات التتظيمية المكانية لبيئة تعليم التتس، أطروحة دكتوراه، جامعة بغداد، كلية التربية الرياضية.

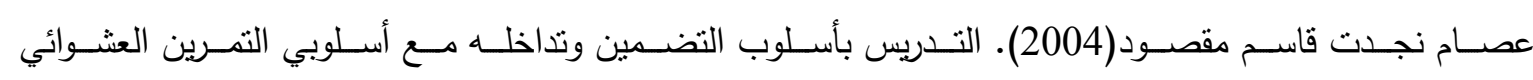
والمتسلسل وأثره في تعلم الطلاب بعض مهارات كرة السلة والأحتفاظ به، رسالة ماجستير ، جامعة بغداد.

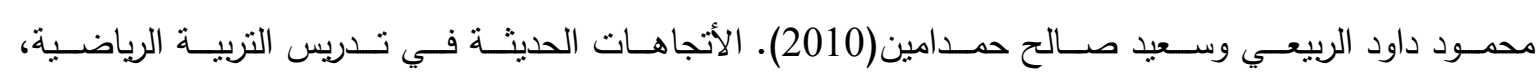
أربيل، مطبعة منارة. مصـطفى السـايح محمــ(2009). أدبيـات البحـث فـي تـدريس التربيـة الرياضــية، ط1، الإســكندرية، دار الوفـاء

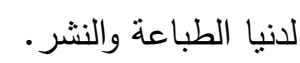

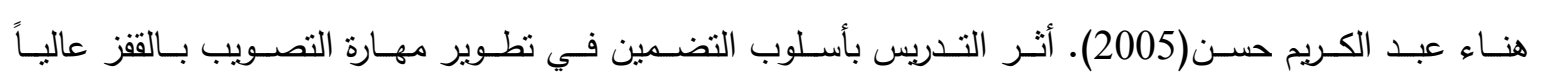
بكرة اليد، بحث منشور في المجلات الأكاديمية العراقية العلمية.

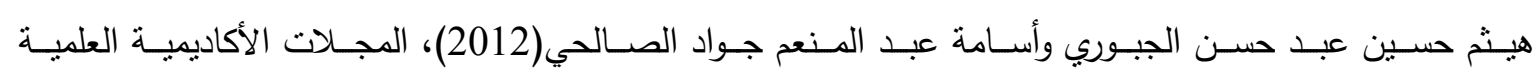
العراقية في علوم التربية الرياضية.

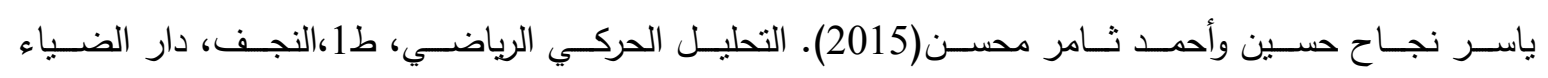
للطباعة.

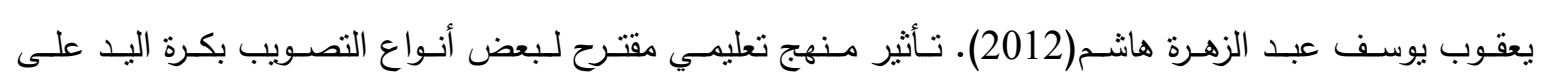
وفق الأنظمة التمثيلية (سمعي- بصري- حسي)، رسالة ماجسنير ، جامعة بغداد. 
ملحق (1) أستمارة تقييم الأداء الحركي (التصويب من القفز عالياً)

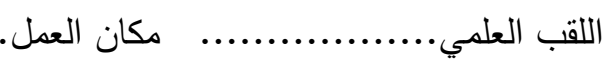

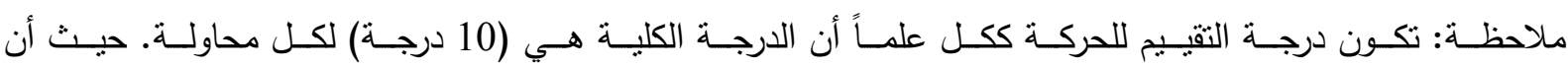

\begin{tabular}{|c|c|c|c|}
\hline المحاولة الثانية & المحاولة الأولى & أسم الطالب & ت \\
\hline & & & 1 \\
\hline & & & 2 \\
\hline & & & 3 \\
\hline & & & 4 \\
\hline & & & 5 \\
\hline & & & 6 \\
\hline & & & 7 \\
\hline
\end{tabular}

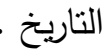

ملحق (2) أسماء الخبراء لتقبيم الأداء الحركي

\begin{tabular}{|c|c|c|c|}
\hline مكان العمل & الأختصاص & الأسم واللقب العلمي & $ت$ \\
\hline كلية التربية البدنية وعلوم الرياضة - & تدريب - كرة يد & أ.د. أحمد خميس راضي & 1 \\
\hline كلية التربية البدنية وعلوم الرياضة - & أختبارات - كرة يد & أ.م.د. فؤاد متعب حسين & 2 \\
\hline كلية التربية البدنية وعلوم الرياضة - & تدريب - كرة يد & أ.م.د. رعد خنجر حمدان & 3 \\
\hline
\end{tabular}

ملحق (3) أسماء فريق العمل المساعد

\begin{tabular}{|c|c|c|c|}
\hline مكان العمل & الأختصاص & الأسم واللقب العلمي & $ت$ \\
\hline طالب دكتوراه - كلية التربية البدنية وعلوم & تدريب - كرة يد & أ.م علي عبداللطيف علي & 1 \\
\hline طالب ماجستير - كلية التربية البدنية وعلوم & تعلم - الكرة الطائرة & حسام حسين دحام & 2 \\
\hline طالب ماجستير - كلية التربية البدنية وعلوم & بايوميكانيك - كرة يد & محمود عباس حسين & 3 \\
\hline
\end{tabular}


ملحق (4)

وحدة تعليمية لتناخل (أسلوب التضمين والتبادلي)

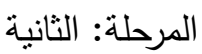
الهذف التعليمي: تعليم مهارة التصويب من القفز عالياً

الهدف التربوي: حث الطلاب عل أحترام أراء الأخرين والتأكيد على التشويق بالأداء الأدوات: (كرات، أقماع، أطواق، مربعات (60×60م)، مصطبة، سلم أرضي، قفاز) التأريخ: 2019/2/24

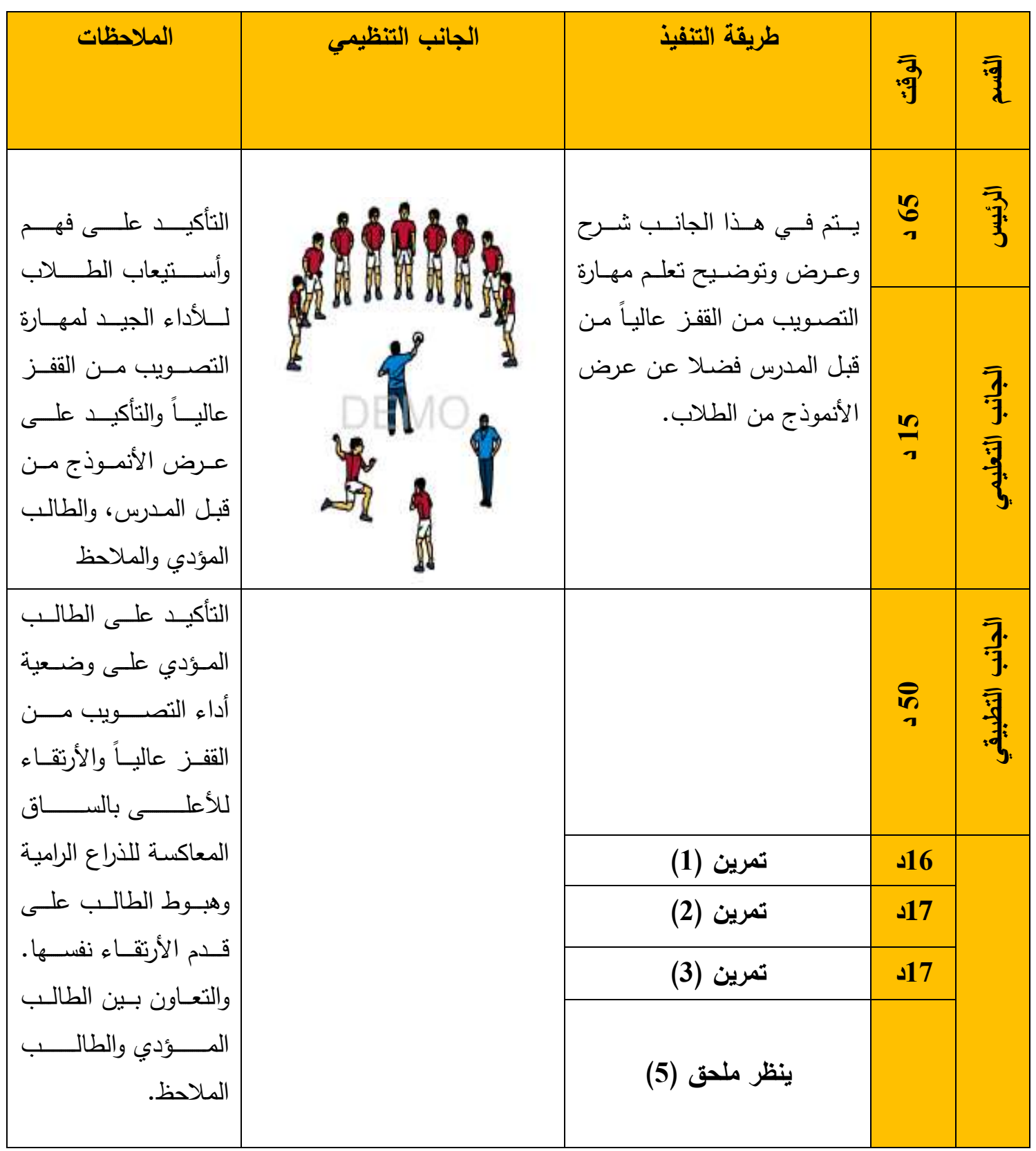


ملحق (5)

التمرينات المستخدمة في الوحدة التعليمية (التصويب من القفز عالياً) (تضمين + تبادلي)

(l)

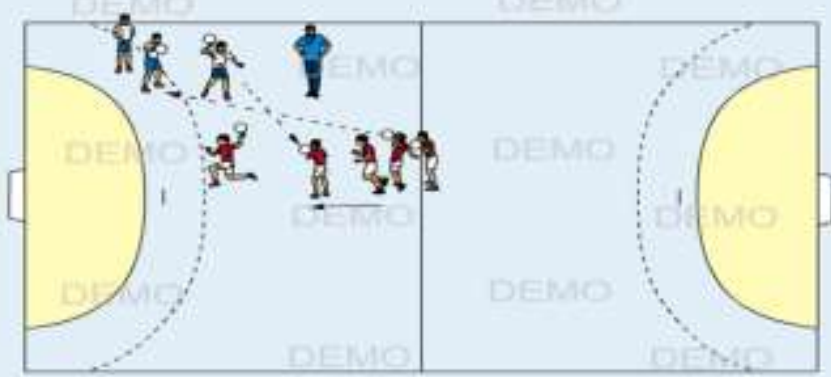

وقـوف الطـلاب على شـكل مجمـوعتين، المجموعـة الأولـى على بعـــ (3م) خـارج خـط (9م) مـع الكـرات والمجموعـة

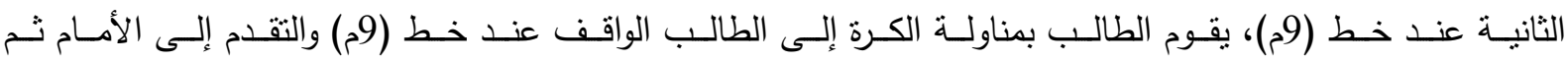
أستلامها والتصويب على المرمى بعد أخذ ثلاث خطوات.

(ب)

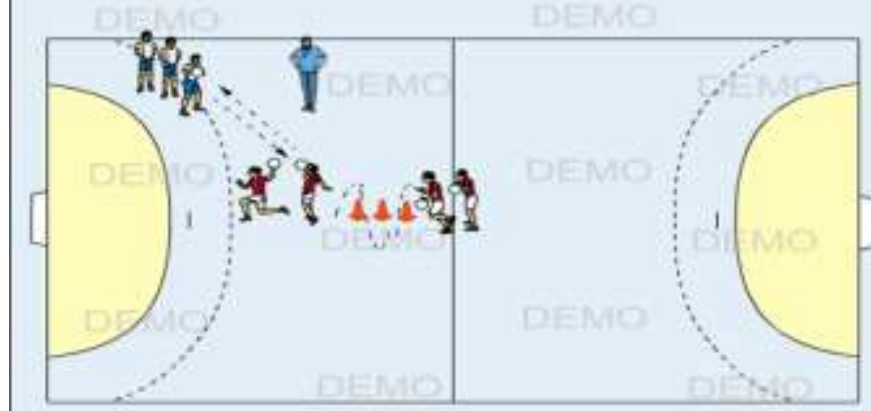

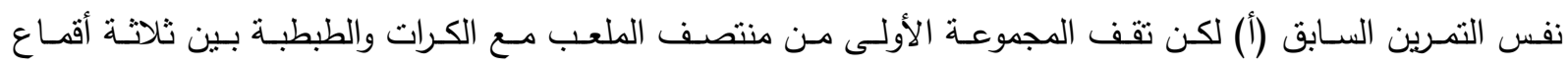
المسافة بينها (2م) ثم مناولة وأستلام والتصويب على المرمى.

(ج)

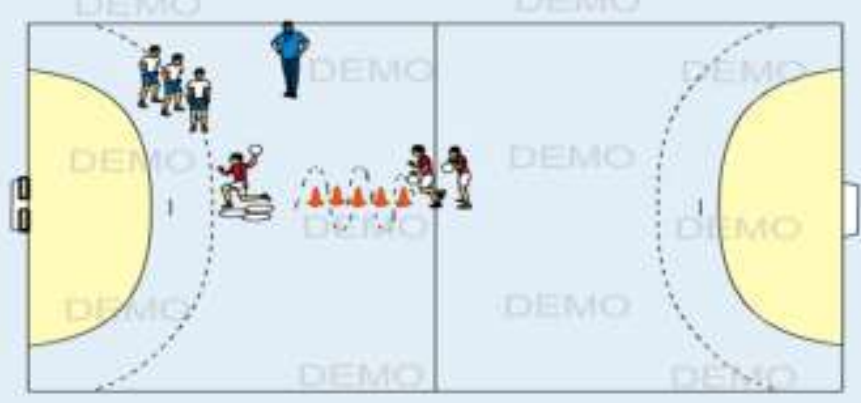

نفس التمرين السابق (ج) لكن الطبطبة بين خمسة أقماع وأداء ثلاث خطوات فوق الأطواق ثم التصويب على مربعات معلقة في الزاويتين العلويتين للمرمى (60×60م). 